\title{
Surgical properties and survival of a pericardial window via left minithoracotomy for benign and malignant pericardial tamponade in cancer patients
}

\author{
Sezai Celik ${ }^{1,3^{*}}$, Muharrem Celik ${ }^{1}$, Bulent Aydemir ${ }^{1}$, Handan Tanrıkulu' ${ }^{1}$, Tamer Okay ${ }^{1}$ and Nurşen Tanrikulu ${ }^{2}$
}

\begin{abstract}
Background: Surgical drainage is a rapid and effective treatment for pericardial tamponade in cancer patients. We aimed to investigate the effectiveness of pericardial window formation via mini-thoracotomy for treating pericardial tamponade in cancer patients, and to evaluate clinical factors affecting long-term survival.

Methods: Records of 53 cancer patients with pericardial tamponade treated by pericardial window formation between 2002 and 2008 were examined. Five patients were excluded due to insufficient data. Kaplan-Meier and Cox regression analysis were used for analysis.

Results: Forty-eight patients (64.7\% male), with a mean age of $55.20 \pm 12.97$ years were included. Patients were followed up until the last control visit or death. There was no surgery-related mortality and the 30-day mortality rate was $8.33 \%$; all died during postoperative hospitalization. Morbidity rate was $18.75 \%$. Symptomatic recurrence rate was $2.08 \%$. Cancer type and nature of the pericardial effusion were the major factors determining long-term survival $(P<0.001$ and $P<0.004$, respectively).

Overall median survival was $10.41 \pm 1.79$ months. One- and 2-year survival rates were $45 \pm 7 \%$ and $18 \pm 5 \%$, respectively.

Conclusion: Pericardial window creation via minithoracotomy was proven to be a safe and effective approach in surgical treatment of pericardial tamponade in cancer patients. Cancer type and nature of pericardial effusion were the main factors affecting long-term survival.
\end{abstract}

Keywords: Pericardial tamponade, Pericardial window, Cancer patients, Long-term survival

\section{Background}

The prevalence of pericardial tamponade requiring surgical intervention is not uncommon in cancer patients and it is a life-threatening problem. It is possible to overcome this problem, prolong survival, and improve the quality of life of patients by effective management strategies. The essence of management is to achieve minimal morbidity and longterm survival without procedure-related mortality. The effectiveness of creating a pericardiopleural window via left

\footnotetext{
* Correspondence: siyamie@gmail.com

'Department of Thoracic Surgery, Siyami Ersek Thoracic and Cardiovascular

Surgery Training and Research Hospital, Istanbul, Turkey

${ }^{3}$ Fatih Sultan Mehmet Mah. Balkan cad, Yesilvadi Evleri A3 Blok D: 36,

Istanbul, Umraniye 34771, Turkey

Full list of author information is available at the end of the article
}

minithoracotomy for the surgical treatment of pericardial tamponade in cancer patients, and the associated risk factors affecting long-term survival were investigated in this study.

\section{Methods}

A total of 48 consecutive cancer patients with pericardial tamponade treated by creating a pericardial window via left mini-thoracotomy between February 2002 and January 2008 in our clinic were included in the study. The study was approved by the Local Ethics Committee. Patients, who underwent pericardiocentesis alone, those who had sclerotherapy along with pericardiocentesis, and those who were concurrently diagnosed with pericardial tamponade along with malignity, were excluded.

\section{Biomed Central}


During the study period, 22 patients with symptomatic pericardial effusion were treated by pericardiocentesis alone with no recurrence. These patients were directed to chemotherapy and mediastinal radiotherapy.

The mean age of the patients was $55.20 \pm 12.97$ years (range, 25-73 years), and 16 (33\%) were female and 32 (64.7\%) were male. All clinical information including the surgical procedure and complications, preoperative and postoperative echocardiography findings, cytopathological, cytogenetic, bacteriological, viral and immunological results, and patient outcome was retrospectively reviewed from patient files.

The diagnosis of pericardial tamponade was based on clinical features as well as the presence of at least one of the following criteria observed by standard M Mode, two-dimensional and Doppler echocardiography [1]: (1) right atrial collapse and right ventricular diastolic collapse; (2) an inspiratory decrease in peak mitral flow more than $30 \%$ (normal value, $<10 \%$ ), greater than $50 \%$ inspiratory increase in peak tricuspid inflow velocity (normal value, <25\%); (3) dilated vena cava without any inspiratory collapse; (4) systolic anterior motion of the mitral valve; (5) swinging of the heart within the pericardium, 'swinging heart'.

\section{Surgical technique}

All patients were operated under general anesthesia with endotracheal intubation. The pericardium was exposed via a left minithoracotomy through the fourth intercostal space (a submammarian incision of 4 to $5 \mathrm{~cm}$ ) using a pediatric chest wall retractor. After identification of the phrenic nerve, an anterolateral pericardial window of $4 \times 4$ or $5 \times 5 \mathrm{~cm}$ was opened over the left ventricle, or if the tamponade was due to posterior fluid collection, a posterior pericardial window below the phrenic nerve was created. A chest drain ( $\mathrm{Nu} .28 \mathrm{~F})$ was placed by a separate incision. The drain was removed after the daily drainage was reduced to below $100 \mathrm{~mL}$.

\section{Follow-up}

The follow-up of the patients were carried out by faceto-face interviews or over the phone until January 2008. Recurrence was defined as the subsequent occurrence of a symptomatic pericardial tamponade after pericardial window procedure. Survival was defined as the time from the window procedure until the last visit or time of death. Follow-up was performed in all patients, and the mean follow-up duration was $38.86 \pm 9.63$ months.

\section{Statistical method}

Statistical analysis of the data was performed by using Number Cruncher Statistical System (NCSS) 2007\&PASS 2008 statistical software (UT, USA). In addition to descriptive statistical methods, Kruskal Wallis test was used for the comparison of quantitative variables that were not normally distributed between the groups. Student $t$ test was used for the comparison of normally distributed variables between two groups, and Mann Whitney $U$ test was used for the comparison of non-normally distributed variables. The comparison of qualitative variables was performed using the chi-square test and Fisher's exact chi-square test. The Kaplan-Meier method was used for survival analysis.

The prognostic value of the following variables were investigated: age, sex, primary malignancy, pericardial effusion-free interval, the amount and type of effusion drained during surgery, preoperative central venous pressure (CVP), hemoglobin and ejection fraction (EF) values, radiotherapy, distant metastasis, the presence and type of the accompanying pleural effusion, malignant or benign nature of the pericardial tamponade. Multivariate regression analysis of potential risk factors affecting long-term survival was performed by Cox regression analysis. A $P$ value $<0.05$ was considered statistically significant.

\section{Results}

All patients had a previous diagnosis of cancer. Pericardial tamponade occurred during ongoing chemotherapy in 32 patients, and after completion of chemotherapy, either while receiving mediastinal radiotherapy or within 2 months after this procedure, in 13 patients. Three patients were on simultaneous chemotherapy and radiotherapy when the tamponade occurred.

The etiology of pericardial effusions is presented in Table 1. Patient characteristics are presented in Table 2. In our series, 19 patients with symptomatic pericardial effusion underwent a single pericardiocentesis approximately 30 days before the surgery, and intrapericardial bleomycin was administered to four of them. However, these patients were re-admitted to our hospital with clinical signs of pericardial tamponade, and consequently treated with surgery. All patients in this series consented to undergo surgery. In general, the surgical procedure was well tolerated by all patients except one who developed hypotension during surgery. The operative time was $28.26 \pm 3.76 \mathrm{~min}$. The drainage volume during the operation and the postoperative period were $862.5 \pm 390.37 \mathrm{~mL}$ and $450 \pm 280 \mathrm{~mL}$, respectively. The highest drainage volume was obtained from a lung cancer patient with malignant pericardial tamponade, and the lowest drainage volume was obtained from a cervix cancer patient with an idiopathic pericardial effusion with tamponade. While $37.5 \%$ of the pericardial effusion was hemorrhagic, $60.4 \%$ was serous and $2.1 \%$ was purulent. Pericardial effusion was benign in nature in 22 out of 48 patients (45.8\%) and malignant in 26 (54.2\%).

No procedure-related mortality was observed in our study, and the symptomatic recurrence rate was found as $2.08 \%$ (1 patient). The 30 -day mortality including in- 
Table 1 The etiologies of pericardial effusions

\begin{tabular}{ll}
\hline Diagnosis & $\boldsymbol{n}$ \\
\hline Malignancy & 26 \\
Lung cancer & 14 \\
Breast cancer & 5 \\
Hematological malignancy & 4 \\
Other & 3 \\
Benign disorders & 22 \\
Chronic non-specific pericarditis & 15 \\
Lung cancer & 4 \\
Breast cancer & 3 \\
Hematological malignancy & 2 \\
Nasopharyngeal cancer & 1 \\
Cervix cancer & 1 \\
Prostate cancer & 1 \\
Renal cell cancer & 1 \\
Testis cancer & 1 \\
Undifferentiated cancer & 1 \\
Tuberculosis & 1 \\
Mesothelioma & 1 \\
Hematological malignancy & 1 \\
Hypothyroidism & 2 \\
Renal cell cancer & 2 \\
Lrradiation & 1 \\
Bung cancer & 1 \\
\hline Lung cancer & 1 \\
\hline
\end{tabular}

hospital mortality was $8.33 \%$ (4 patients). The causes of 30-day mortality were ventricular fibrillation in one patient, pneumonia and sepsis due to prolonged intubation in one patient, pulmonary embolism in one patient, and low cardiac output in another. Morbidity rate was $18.75 \%$. Information regarding morbidity is presented in Table 3.

In order to improve hemodynamics, pericardiocentesis was performed in all patients just before the surgery, and pericardial window was opened subsequently. Symptomatic pericardial effusion recurred 1 month after the pericardial window procedure in one patient with epidermoid lung cancer (pericardial tamponade due to irradiation), who developed constrictive pericarditis with a small loculated effusion 1 month after the window procedure. Pericardiectomy was performed by median sternotomy in this patient who died due to low cardiac output and failure at postoperative day 20 .
Table 2 Demographic and preoperative data of the patients

\begin{tabular}{|c|c|c|}
\hline & Min-Max & Mean \pm SD \\
\hline Male/female & $32 / 16$ & $64.7 / 33 \%$ \\
\hline Age (years) & $25-73$ & $55.2+12.97$ \\
\hline Pericardial effusion-free interval (months) & $1-48$ & $13.47 \pm 10.34$ \\
\hline $\mathrm{Hb}(\mathrm{g} / \mathrm{dL})$ & $9.6-16$ & $11.65 \pm 1.34$ \\
\hline $\mathrm{EF}(\%)$ & $40-66$ & $54.37 \pm 5.89$ \\
\hline \multirow[t]{2}{*}{ Central venous pressure $\left(\mathrm{cm} \mathrm{H}_{2} \mathrm{O}\right)$} & $15-26$ & $17 \pm 7.6$ \\
\hline & $n$ & $\%$ \\
\hline \multicolumn{3}{|l|}{ Cancer type $(n)$} \\
\hline Breast & 8 & 16.6 \\
\hline Hematologic & 7 & 14.5 \\
\hline Lung & 21 & 43.7 \\
\hline Other & 12 & 25 \\
\hline \multicolumn{3}{|l|}{ Appearance of effusion (n) } \\
\hline Hemorrhagic & 18 & 37.5 \\
\hline Serous & 29 & 60.4 \\
\hline Purulent & 1 & 2.1 \\
\hline \multicolumn{3}{|l|}{ Pericardial effusion type ( $n$ ) } \\
\hline Malignant & 26 & 54.2 \\
\hline Benign & 22 & 45.8 \\
\hline Accompanying pleural effusion (n) & 23 & 47.9 \\
\hline Malignant & 12 & 52.2 \\
\hline Benign & 11 & 47.8 \\
\hline Radiotherapy prior to or during tamponade & 13 & 27 \\
\hline Chemotherapy prior to or during tamponade & 48 & 100 \\
\hline Distant metastasis & 14 & 35.9 \\
\hline Overt tamponade & 48 & 100 \\
\hline Prior pericardiocentesis & 19 & 40 \\
\hline
\end{tabular}

SD, standard deviation.

\section{Survival analysis}

Among 48 patients included in the study, four (8.3\%) of them died during the hospitalization period and 36 (75\%) died during follow-up. Eight patients (16.7\%) were still alive at the end of the follow-up period. The mean survival time was $10.41 \pm 1.79$ months. One-year survival rate was $45 \pm 7 \%$ and 2-year survival rate was $18 \pm 5 \%$ (Figure 1).

The risk factors affecting survival are presented in Table 4. Overall survival did not differ significantly according to sex, the presence, appearance, and the type of the accompanying pleural effusion, radiotherapy, recurrence, and the presence of distant metastasis. However, a statistically significant difference was observed between the survival durations of patients with various cancer types $(P<0.01)$. Comparison of paired groups revealed that survival time in the hematological malignancy group was significantly longer compared to that 
Table 3 Operative and postoperative data of the patients

\begin{tabular}{ll}
\hline Operative time, min & $28.26 \pm 3.76$ \\
Drainage volume during surgery, $\mathrm{mL}$ & $862.5 \pm 390.37$ \\
Postoperative effusion drained, $\mathrm{mL}$ & $450 \pm 280$ \\
Duration of drainage, days & $6.00 \pm 1.46$ \\
Postoperative CVP ( $\left.\mathrm{cmH}_{2} \mathrm{O}\right)$ & $9.5 \pm 3.2$ \\
Length of hospital stay, days & $9.5 \pm 7.2$ \\
30-day mortality & $4(8.33 \%)$ \\
Postoperative complications & $7(14.5 \%)$ \\
Heart failure & $1(2.08 \%)$ \\
Arrhythmia & $1(2.08 \%)$ \\
Pulmonary embolus & $1(2.08 \%)$ \\
Pneumonia & $1(2.08 \%)$ \\
Prolonged ventilation & $1(2.08 \%)$ \\
Wound infection & $2(4.1 \%)$ \\
Follow-up, months & $38.86 \pm 9.63$ \\
Recurrence requiring intervention & $1(2.08 \%)$ \\
\hline
\end{tabular}

CVP, central venous pressure.

Data are given as number (percentage) and Mean $\pm S D$, where appropriate.

in lung cancer and other cancer groups $(P=0.001$ and $P=0.019$, respectively), and survival time in breast cancer group was significantly longer compared to that in lung cancer group ( $P=0.014$; Figure 2$)$. Patients with malignant pericardial effusion had a significantly shorter survival time in compared to that of patients with benign pericardial effusion $(P<0.01$; Figure 3$)$.

The results of correlation analysis between quantitative parameters and survival are presented in Table 5 .

A statistically significant negative correlation was found between age and survival time $(r=-0.401$, $P=0.005)$. Survival time decreased with increasing age. Hemoglobin levels and survival time was positively correlated $(r=0.463, P=0.001)$. Furthermore, there was a

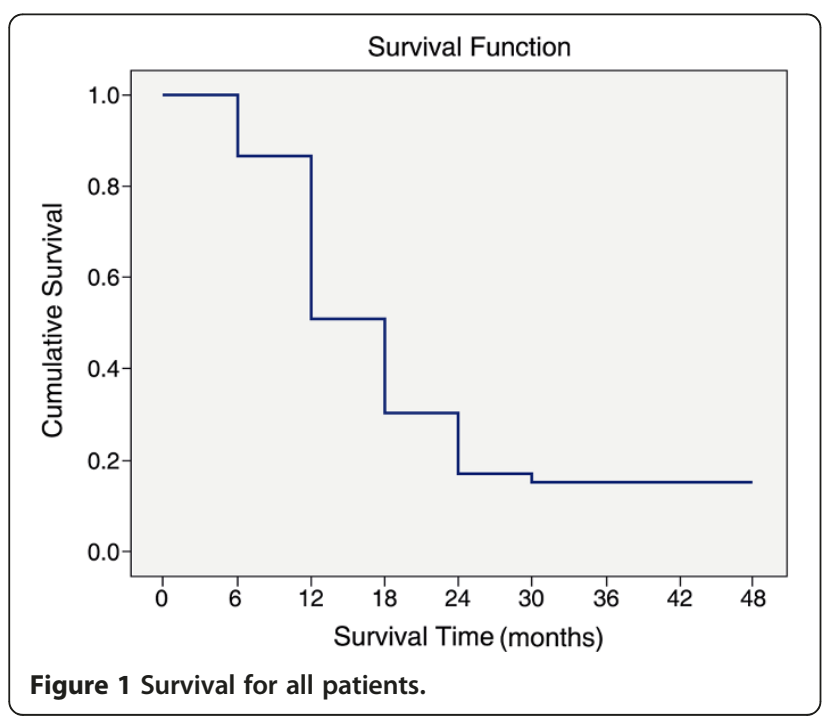

Table 4 Risk factors affecting survival

\begin{tabular}{|c|c|c|c|}
\hline & \multicolumn{2}{|c|}{ Survival (months) } & \multirow[t]{2}{*}{$P$} \\
\hline & Mean \pm SD & Median & \\
\hline \multicolumn{4}{|l|}{ Gender } \\
\hline Female & $17.43 \pm 9.81$ & 16 & 0.476 \\
\hline Male & $15.07 \pm 9.59$ & 11 & \\
\hline \multicolumn{4}{|l|}{ Cancer type $^{\mathrm{b}}$} \\
\hline Breast & $19.71 \pm 6.98$ & 21 & \\
\hline Hematologic & $29.20 \pm 7.59$ & 33 & $0.001^{\mathrm{b}}$ \\
\hline Lung & $11.79 \pm 6.26$ & 11 & \\
\hline Other & $15.84 \pm 11.57$ & 11 & \\
\hline \multicolumn{4}{|l|}{ Pleural effusion } \\
\hline Present & $14.44 \pm 8.38$ & 11 & 0.420 \\
\hline Absent & $17.16 \pm 10.65$ & 12 & \\
\hline \multicolumn{4}{|c|}{ Macroscopic appearance of the effusion } \\
\hline Hemorrhagic & $13.85 \pm 10.12$ & 11 & 0.136 \\
\hline Serous & $17.24 \pm 9.39$ & 15 & \\
\hline \multicolumn{4}{|c|}{ Nature of the pleural effusion } \\
\hline Malignant & $14.91 \pm 10.6$ & 9.5 & 0.347 \\
\hline Benign & $14.72 \pm 6.19$ & 12 & \\
\hline \multicolumn{4}{|l|}{ Radiotherapy } \\
\hline Present & $15.07 \pm 8.20$ & 12 & 0.701 \\
\hline Absent & $17.16 \pm 11.77$ & 12.5 & \\
\hline \multicolumn{4}{|c|}{ Distant metastasis } \\
\hline Present & $14.73 \pm 7.99$ & 11.5 & 0.942 \\
\hline Absent & $14.80 \pm 8.41$ & 12 & \\
\hline \multicolumn{4}{|c|}{ Nature of the pericardial effusion } \\
\hline Malignant & $11.89 \pm 8.78$ & 9.5 & $0.004^{*}$ \\
\hline Benign & $18.36 \pm 9.58$ & 16.5 & \\
\hline
\end{tabular}

SD, standard deviation.

Mann Whitney $U$ test.

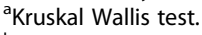

${ }^{\mathrm{b}} \mathrm{P}<0.01$.

statistically significant positive correlation between the pericardial effusion-free interval and survival time $(\mathrm{r}=0.292, \quad P=0.044)$. No significant correlation was noted between survival time and the amount of effusion removed, preoperative CVP, and EF $(P>0.05$ for all parameters).

The variables, which were found to be significant or close to significance by univariate analysis, were evaluated by Cox regression analysis. Age above 55 years and lung cancer were found as significant factors affecting survival. Lung cancer increased the risk of mortality by 1.997-fold (95\% CI: 1.004-3.973). Although age was a significant risk factor, the odds ratio for age was only 0.351 (95\% CI: 0.175-0.704) (Table 6).

Assessment of survival rates according to the nature of pericardial effusion by Log Rank test revealed a significant 


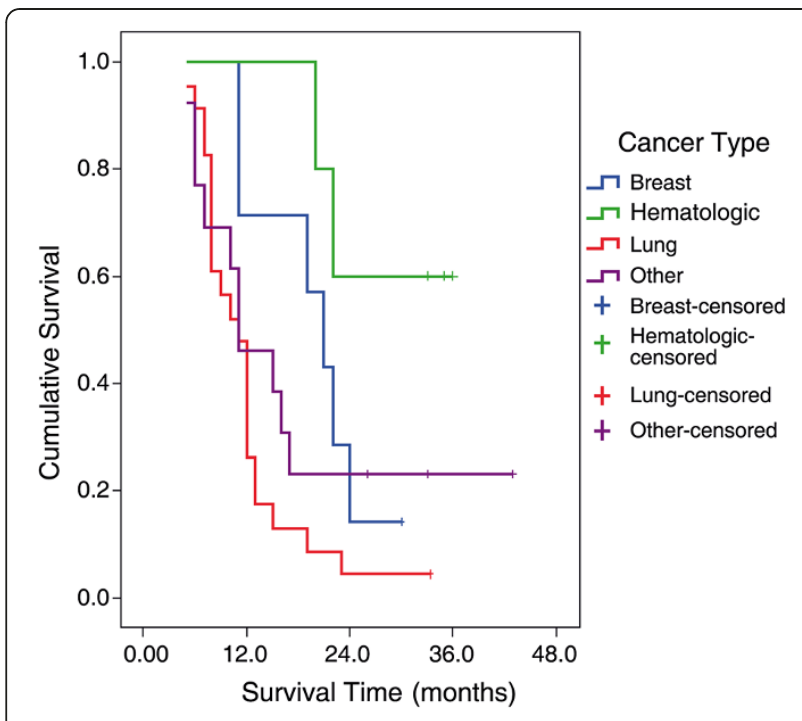

Figure 2 Survival for patients with cancer by tumor type.

difference $(P=0.019 ; P<0.05)$. The survival time was shorter in patients with malignant effusions (Figure 3 ).

\section{Discussion}

Pericardial effusion is less common than pleural effusion in cancer patients; however, it often has an acute onset, and may be a direct cause of death if it leads to tamponade, and is not effectively treated. The ideal management of this life-threatening condition involves urgent decompression of the pericardial cavity, obtaining sufficient amount of fluid and tissue sample for the identification of the exact cause of tamponade, prevention of recurrence, and targeting a long survival period with the

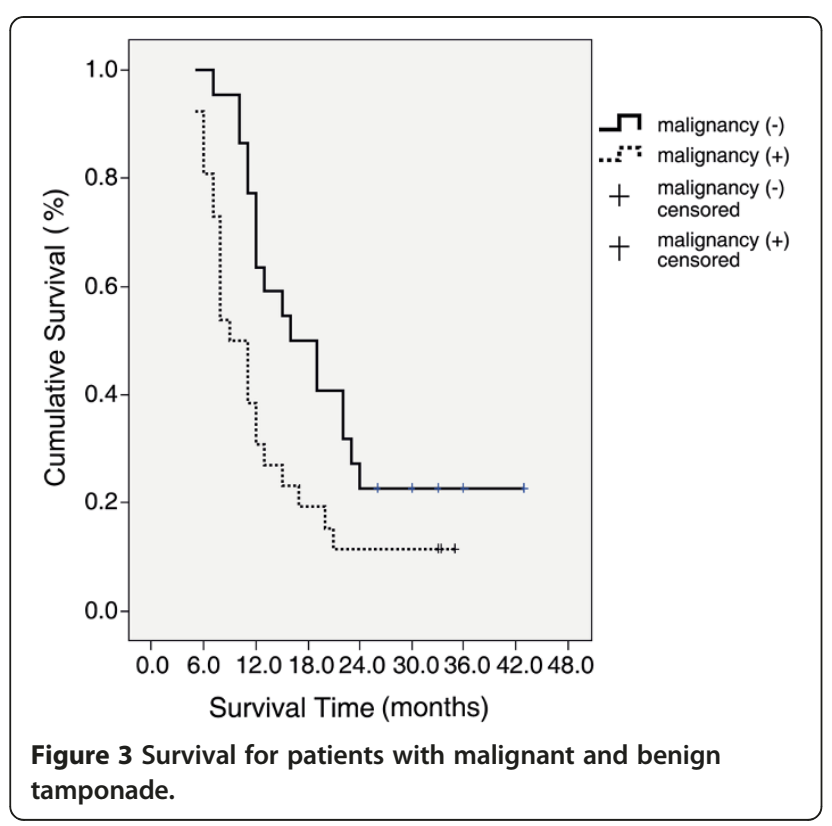

Table 5 Results of correlation analysis between quantitative parameters and survival

\begin{tabular}{lll}
\hline & \multicolumn{2}{c}{ Survival (months) } \\
\cline { 2 - 3 } & $\mathbf{r}$ & $\boldsymbol{P}$ \\
\hline Age & -0.401 & $0.005^{\mathrm{a}}$ \\
Amount of effusion removed during surgery $(\mathrm{mL})$ & -0.220 & 0.134 \\
Preoperative $\mathrm{Hb}(\mathrm{g} / \mathrm{dL})$ & 0.463 & $0.001^{\mathrm{a}}$ \\
Preoperative EF (\%) & 0.193 & 0.189 \\
Pericardial effusion-free interval (months) & 0.292 & $0.044^{\mathrm{b}}$ \\
Preoperative CVP (cmH20) & 0.174 & 0.168 \\
\hline
\end{tabular}

$\mathrm{CVP}$, central venous pressure; $\mathrm{EF}$, ejection fraction; $\mathrm{Hb}$, hemoglobin. $\mathrm{R}$, Spearman's rho coefficient.

${ }^{\mathrm{a}} P<0.01$.

${ }^{\mathrm{b}} P<0.05$.

accomplishment of all of these goals with the lowest possible morbidity and mortality. Principally, pericardiocentesis procedure does not fulfill these criteria due to high recurrence rates [2-4]. Recent studies have suggested surgical pericardial window procedure instead of pericardiocentesis in patients with pulmonary adenocarcinoma who achieve a longer life expectancy by chemotherapy [5]. Bitran et al. [6] reported that creation of a pericardial window improved survival time in breast cancer patients who developed pericardial tamponade. However, it might still be necessary to perform pericardiocentesis prior to pericardial window procedure to prevent sudden low cardiac output. It has been reported by Olsen et al. [7] that creating a pericardial window through left minithoracotomy is a rapid, simple, and inexpensive technique, which we have also been routinely performing for a long period of time, especially in cases of pericardial tamponade. Olsen et al. [7] created a pericardial window in 28 patients with large malignant pericardial effusions using this method and reported that the postoperative mortality was $21 \%$. There were no procedure-related intra- or postoperative death, and symptomatic recurrence was noted in only one patient. We particularly included cancer patients with pericardial tamponade in our study, as there is currently no sufficient information or consensus regarding the management of this condition in cancer patients. Gregory et al. [8] treated pericardial tamponade by creating a window through anterolateral thoracotomy in 49 cancer patients, and reported the in-hospital mortality as $8 \%$ and the rate of recurrence as $6 \%$. We did not observe any procedure-related mortality in our series and the recurrence rate was $2.08 \%$. The 30 -day mortality including inhospital mortality was $8.33 \%$ (4 patients). The patient who died due to pneumonia and sepsis secondary to prolonged intubation had both chronic obstructive pulmonary disease and a body mass index $(\mathrm{BMI})>28$. Another patient who died of pulmonary embolism in this group had a previous history of pulmonary embolism. Death occurred due to ventricular fibrillation in one patient with a previous 
Table 6 Results of univariate and multivarite Cox Regression analysis for potential risk factors affecting survival

\begin{tabular}{|c|c|c|c|c|c|c|c|c|}
\hline & \multicolumn{4}{|c|}{ Univariate } & \multicolumn{4}{|c|}{ Multivariate (Cox Regression) } \\
\hline & \multirow[t]{2}{*}{$P$} & \multirow[t]{2}{*}{ Odds } & \multicolumn{2}{|l|}{$95 \% \mathrm{Cl}$} & \multirow[t]{2}{*}{$P$} & \multirow[t]{2}{*}{ Odds } & \multicolumn{2}{|l|}{$95 \% \mathrm{Cl}$} \\
\hline & & & Lower & Upper & & & Lower & Upper \\
\hline Age $>55$ years & $0.002^{a}$ & 0.607 & 0.502 & 0.885 & $0.003^{b}$ & 0.351 & 0.175 & 0.704 \\
\hline$E F<50$ & 0.210 & 3.769 & 0.420 & 33.80 & 0.221 & 1.536 & 0.773 & 3.055 \\
\hline Lung cancer & $0.028^{b}$ & 8.556 & 1.161 & 77.13 & $0.045^{\mathrm{b}}$ & 1.997 & 1.004 & 3.973 \\
\hline
\end{tabular}

${ }^{\mathrm{a}} P<0.01$.

${ }^{\mathrm{b}} P<0.05$.

$E F$, ejection fraction.

history of ischemic heart disease, and low cardiac output in another patient with chronic ischemic heart disease. No late pericardial constriction was noted in patients with long survival rates.

The major reason for preferring left minithoracotomy for creating a pericardial window in our clinic for years is that this group of patients need prompt and definitive diagnosis and treatment. This technique is advantageous as it does not require single-lung ventilation, it can be applied in only 25 to $30 \mathrm{~min}$, it provides the opportunity for opening a larger window, thus allows obtaining a larger tissue sample with a greater chance of histopathological diagnosis, and it offers the opportunity for pleural biopsy. Moreover, mini-submammary incision is much more cosmetic compared to subxiphoid lengthwise incision. The most important disadvantage of the technique is the risk of sudden hypotension during induction of general anesthesia, but this risk can be overcome by a pericardiocentesis performed right before the procedure. For this reason, echo-guided pericardiocentesis was performed in all patients before the pericardial window procedure in our study, and no intraoperative problems were encountered in these patients. Postoperative pain can easily be controlled via a patient-controlled anesthesia pump. According to our experience, pericardial window procedure is associated with a specific disadvantage, which is the difficulty of performing left minithoracotomy in breast cancer patients with previous left mastectomy and subsequent radiotherapy. The presence of excessive adhesions involving the pericardium, mediastinal tissues and chest wall is highly likely in these cases, and this might increase the odds of myocardial rupture during thoracotomy and exploration. Moreover, it might also be difficult to perform minithoracotomy in obese individuals and women with large breasts. Other methods should be considered in these cases.

Video-assisted thoracic surgery (VATS) procedure is nearly impossible, especially in cases where single-lung ventilation cannot be performed due to hemodynamic instability. Actually, the number of studies on VATS pericardial window in hemodynamically unstable cancer patients with pericardial tamponade remains limited. This indicates that the effective use of VATS in this patient group continue to be a problem. In their study, Georghiou et al. [9] created a pericardial window via VATS in 18 patients and stated that VATS had the advantages of both subxiphoid pericardiotomy and pericardiectomy. In their series, however, there was no hemodynamically unstable patient with cardiac tamponade. Fibla et al. [10] reported that eight of twelve patients with cancer who had pericardial tamponade were treated effectively with VATS. As we apply VATS in selected patients, these patients have not been included in the present study.

Although decompression of the pericardial cavity by subxiphoid approach under local anesthesia is an easier technique to perform, it is essentially equivalent to tube thoracostomy, and is associated with high recurrence rates. Therefore, creating a pericardial window by subxiphoid method should not be preferred in patients with a high probability of long-term survival. In the study by O'Brien et al. [11], in which subxiphoid approach and VATS were compared, patients with hemodynamic instability did not constitute the majority. They reported the recurrence rate of pericardial effusion to be $8 \%$ after VATS. In a prospective study [12] including 30 patients, of which 15 (10 with tamponade) underwent VATS and 15 (seven with tamponade) underwent surgical procedure (transthoracic or subxiphoid), no significant difference was found in terms of intra- or postoperative complications, mortality, duration of drainage, duration of hospitalization, and recurrence; however, operative time was reported to be significantly longer in those undergoing VATS. Becit et al. [13] reported a recurrence rate of $10 \%$ within 1 month of subxiphoid surgical pericardiostomy in 368 patients with pericardial effusions (most of them had pericarditis associated with tuberculosis and uremia) and they created a pericardial window by left anterior thoracotomy in these patients with no subsequent recurrence. Mueller et al. [14] reported an overall success rate of $82 \%$ for subxiphoid pericardial window procedure in their series of 67 patients (26 cancer-related; 14 malignant pericardial effusions). In a prospective study from Duke University, surgical subxiphoid pericardiotomy was done under local anesthesia in $77 \%$ of 57 patients with various diseases, with general 
anesthesia required in the others. Effusion recurred in eight patients in 2 months and in nine (16\%) in the first year.

We also found that the presence of malignant pericardial tamponade was a negative risk factor for long-term survival. Contradictory findings have been reported in previous studies using various surgical techniques, some supporting $[14,15]$ and some not supporting [16,17] our results. Wang et al. [18] reported that there was no significant difference between survival rates of malignant $(n=60)$ and benign $(n=20)$ pericardial effusion cases. We found a significant difference between these groups in our study. It should also be noted that the overall median survival found in our study was longer compared to previous reports. Olsen et al. [7] reported in patients with malignant effusion treated by minithoracotomy pericardial window that the 6-month survival rate was $46 \%$, the 1 -year survival rate was $26 \%$, and the 2-year survival rate was $15 \%$. These results are similar to the median survival rates noted in our series. However, the factors affecting survival were not analyzed in their study.

On the other hand, the use of minimally invasive treatments has been previously studied in this group of patients; however, these treatments have not been currently implemented in routine clinical practice due to various reasons. Drainage with percutaneous catheter in patients with cardiac tamponade can be applied in the intensive care units and is a less invasive method. Nonetheless, the associated complication and recurrence rates are high. In their series of 42 patients, Kopecky et al. [19] reported the complication rate to be $2.4 \%$ and the recurrence rate to be $24 \%$. In the study by Chow et al. [20], pericardial window formation via percutaneous balloon catheter was defined; however, sufficient experience has not yet been gained for the use of this method.

The mean survival time in hematological malignancies was found as $29.20 \pm 7.59$ (33) months in our study. Similar results were also reported in studies using subxiphoid pericardial window technique [21]. Certainly, the long survival times in our patients can primarily be attributed to the advances in systemic treatment. The high number of cases with solid organ cancers in our study population can also explain our findings.

Currently, no standardization exists among chest surgeons as to which procedure should be used to treat pericardial tamponade in cancer patients. Based on our findings, we suggest that creating a pericardial window by minithoracotomy should be preferred as a definitive surgical procedure with the lowest recurrence rates, especially in patients with long-term survival expectancy.

Our study has several limitations including its retrospective nature, the relatively small sample size, and heterogeneity of the study population, which limits the generalization of our findings to the general population.

\section{Conclusions}

In conclusion, creation of a pleuropericardial window by left minithoracotomy provides a prompt, safe, and effective diagnostic and treatment approach, especially in selected cases of both malignant and benign pericardial tamponade occurring in cancer patients. Moreover, the likelihood of recurrence of pericardial effusion is rather low with this technique. Type of the underlying cancer and nature of the pericardial effusion were noted as the main factors affecting long-term survival in our patients.

\section{Abbreviations}

BMl: Body mass index; CVP: Central venous pressure; EF: Ejection fraction; NCSS: Number cruncher statistical system; VATS: Video-assisted thoracic surgery.

\section{Competing interest}

The authors declare that they have no conflict of interest.

\section{Authors' contribution}

SC: design, acquisition of data, analysis and interpretation of data, have given final approval of the version to be published. MC: have been involved in drafting the manuscript or revising it critically for important intellectual content, analysis of data, participated in the sequence alignment. BA: conceived of the study, and participated in its design and coordination and helped to draft the manuscript. HT: participated in the design of the study and performed the statistical analysis. TO: have made substantial contributions to conception and design, or acquisition of data, or analysis and interpretation of data. NT: participated in the design of the study and performed the statistical analysis. Involved in drafting the manuscript. All authors read and approved the final manuscript.

\section{Acknowledgements}

None declared.

\section{Author details}

${ }^{1}$ Department of Thoracic Surgery, Siyami Ersek Thoracic and Cardiovascular Surgery Training and Research Hospital, Istanbul, Turkey. ${ }^{2}$ Department of Anesthesiology and Reanimation, Siyami Ersek Thoracic and Cardiovascular Surgery Training and Research Hospital, Istanbul, Turkey. ${ }^{3}$ Fatih Sultan Mehmet Mah. Balkan cad, Yesilvadi Evleri A3 Blok D: 36, Istanbul, Umraniye 34771, Turkey.

Received: 20 February 2012 Accepted: 2 June 2012

Published: 28 June 2012

\section{References}

1. Mercé J, Sagristà-Sauleda J, Permanyer-Miralda G, Evangelista A, Soler-Soler J: Correlation between clinical and Doppler echocardiographic findings in patients with moderate and large pericardial effusion: implications for the diagnosis of cardiac tamponade. Am Heart J 1999, 138:759-764.

2. Apodaca-Cruz A, Villarreal-Garza C, Torres-Avila B, Torres J, Meneses A, Flores-Estrada D, Lara-Medina F, Arrieta O: Effectiveness and prognosis of initial pericardiocentesis in the primary management of malignant pericardial effusion. Interact Cardiovasc Thorac Surg 2010, 11:154-161.

3. Gumrukcuoglu HA, Odabasi D, Akdag S, Ekim H: Management of cardiac tamponade: a comperative study between echo-guided pericardiocentesis and surgery-a report of 100 patients. Cardiol Res Pract 2011, 2011:197838.

4. Laham RJ, Cohen DJ, Kuntz RE, Baim DS, Lorell BH, Simons M: Pericardial effusion in patients with cancer: outcome with contemporary management strategies. Heart 1996, 75:67-71.

5. Kim SH, Kwak MH, Park S, Kim HJ, Lee HS, Kim MS, Lee JM, Zo Jl, Ro JS, Lee JS: Clinical characteristics of malignant pericardial effusion associated with recurrence and survival. Cancer Res Treat 2010, 42:210-216.

6. Bitran JD, Evans R, Brown C: The management of cardiac tamponade in patients with breast cancer. J Surg Oncol 1984, 27:42-44. 
7. Olsen PS, Sørensen C, Andersen HO: Surgical treatment of large pericardial effusions. Etiology and long-term survival. Eur J Cardiothorac Surg 1991, 5:430-432.

8. Gregory JR, McMurtrey MJ, Mountain CF: A surgical approach to the treatment of pericardial effusion in cancer patients. Am J Clin Oncol 1985, 8:319-323.

9. Georghiou GP, Stamler A, Sharoni E, Fichman-Horn S, Berman M, Vidne BA, Saute M: Video-assisted thoracoscopic pericardial window for diagnosis and management of pericardial effusions. Ann Thorac Surg 2005, 80:607-610.

10. Fibla JJ, Molins L, Mier JM, Vidal G: Pericardial window by videothoracoscope in the treatment of pericardial effusion and tamponade. Cir Esp 2008, 83:145-148.

11. O'Brien PK, Kucharczuk JC, Marshall MB, Friedberg JS, Chen Z, Kaiser LR, Shrager JB: Comparative study of subxiphoid versus video-thoracoscopic pericardial "window". Ann Thorac Surg 2005, 80:2013-2019.

12. Muhammad MI: The pericardial window: is a video-assisted thoracoscopy approach better than a surgical approach? Interact Cardiovasc Thorac Surg 2011, 12:174-178.

13. Becit N, Unlü Y, Ceviz M, Koçogullari CU, Koçak H, Gürlertop Y: Subxiphoid pericardiostomy in the management of pericardial effusions: case series analysis of 368 patients. Heart 2005, 91:785-790.

14. Mueller XM, Tevaearai HT, Hurni M, Ruchat P, Fischer AP, Stumpe F, von Segesser LK: Long-term results of surgical subxiphoid pericardial drainage. Thorac Cardiovasc Surg 1997, 45:65-69.

15. Van Trigt P, Douglas J, Smith PK, Campbell PT, Wall TC, Kenney RT, O'Connor CM, Sheikh KH, Corey GR: A prospective trial of subxiphoid pericardiotomy in the diagnosis and treatment of large pericardial effusion. A follow-up report. Ann Surg 1993, 218:772-778.

16. Mills SA, Julian S, Holliday RH, Vinten-Johansen J, Case LD, Hudspeth AS, Tucker WY, Cordell AR: Subxiphoid pericardial window for pericardial effusive disease. J Cardiovasc Surg (Torino) 1989, 30:768-773.

17. Moores DW, Allen KB, Faber LP, Dziuban SW, Gillman DJ, Warren WH, Ilves $R$, Lininger L: Subxiphoid pericardial drainage for pericardial tamponade. J Thorac Cardiovasc Surg 1995, 109:546-551.

18. Wang PC, Yang KY, Chao JY, Liu JM, Perng RP, Yen SH: Prognostic role of pericardial fluid cytology in cardiac tamponade associated with nonsmall cell lung cancer. Chest 2000, 118:744-749.

19. Kopecky SL, Callahan JA, Tajik AJ, Seward JB: Percutaneous pericardial catheter drainage: report of 42 consecutive cases. Am J Cardiol 1986, 58:633-635.

20. Chow WH, Chow TC, Yip AS, Cheung KL: Inoue balloon pericardiotomy for patients with recurrent pericardial effusion. Angiology 1996, 47:57-60.

21. Dosios T, Theakos N, Angouras D, Asimacopoulos P: Risk factors affecting the survival of patients with pericardial effusion submitted to subxiphoid pericardiostomy. Chest 2003, 124:242-246.

doi:10.1186/1477-7819-10-123

Cite this article as: Celik et al.: Surgical properties and survival of a pericardial window via left minithoracotomy for benign and malignant pericardial tamponade in cancer patients. World Journal of Surgical Oncology 2012 10:123.

\section{Submit your next manuscript to BioMed Central and take full advantage of:}

- Convenient online submission

- Thorough peer review

- No space constraints or color figure charges

- Immediate publication on acceptance

- Inclusion in PubMed, CAS, Scopus and Google Scholar

- Research which is freely available for redistribution 